\title{
Patients' Understanding and Use of Snack Food Package Nutrition Labels
}

\author{
Allen L. Pelletier, MD, Wayne W. Chang, MS, John E. Delzell Jr., MD, MSPH, and \\ John W. McCall, PhD
}

Purpose: Little information exists on how patients in medical practice use food package nutrition labels. We theorized that patients in a general medical practice might not make the distinction between serving size and total package nutrition information, and this might lead to obesity.

Methods: Ninety patients between ages of 18 and 65 attending the St. Francis/University of Tennessee Family Practice Center were interviewed to determine whether they could calculate the total calories in sample snack food packages that contained more than one serving.

Results: Ninety percent of our patient sample correctly identified the number of calories per individual serving, but only $37 \%$ were able to recognize that the sample packages contained multiple servings. Confusion between calories per serving size and total calories per package was correlated with lower educational levels $(P=.011)$ and with the presence of cardiovascular heart disease in our patient sample.

Conclusions: Our patients tended to think of a multiple serving package as one serving. They underestimated and under-reported caloric intake from snack food sources. We conclude that snack food labels as actually used by patients do not lead to informed dietary choices. These findings could impact our understanding and management of the obesity epidemic in the United States. (J Am Board Fam Pract 2004;17:319-23.)

The United States is facing an unprecedented epidemic of obesity. Obesity is commonly assessed by calculating the body mass index (BMI), which is the weight in kilograms divided by height in meters squared. The median percentage of obese adults $(\mathrm{BMI}>30)$ in the United States has increased from $11.6 \%$ in 1990 to $20.1 \%$ in $2001 .^{1,2}$ Obesity and a sedentary lifestyle impose a substantial health risk. According to a recent report by the Surgeon General, ${ }^{3}$ obesity is an important factor in up to 300,000 deaths each year in the United States. Even modest increases of 10 to 20 pounds over

Submitted, revised, 25 June 2004.

From the St. Francis Family Practice Residency Program (ALP, JED) and Department of Family Medicine (JWM), University of Tennessee School of Medicine, Memphis, and Cardiac Rhythm Management Division, St. Jude Medical, Inc., Sylmar, CA (WWC). Address correspondence to Allen L. Pelletier, MD, University of Tennessee/St. Francis Family Practice Center, 1301 Primacy Parkway, Memphis, TN 38119 (e-mail: apelletier@utmem.edu).

This work was supported by a 2001 Student Research Scholarship in Cardiovascular Disease and Stroke from the American Heart Association to WWC. This work was presented previously at the Student/Resident Research Forum, Tennessee Academy of Family Physicians Annual Meeting and Scientific Assembly, 2001 Oct 30-Nov 2; Gatlinburg, Tennessee; and as a poster at the National Student Research Forum; 2002 Apr 25-27; Galveston, Texas. ideal body weight are associated with measurable differences in the risk of adult onset diabetes, hypertension, myocardial infarction, and stroke. Obese persons have a $50 \%$ to $100 \%$ higher risk of all-cause mortality than those with a normal BMI of 20 to $25^{3}$

There is increasing evidence of a positive correlation between snack food and/or fast food consumption and rising rates of obesity in the US population. ${ }^{3-5}$ Several studies have concluded that consumers do not understand food package nutrition information as it is currently provided. ${ }^{6,7}$ Studies regarding food labels and fast food intake have been based on population surveys and questionnaires of college students. ${ }^{8}$ These studies may not be representative of patients in a general medical practice. There is no accurate information regarding the snack food intake of patients in a primary care practice.

Since 1990, US law has mandated that all food packages contain nutrition information in a label form. ${ }^{9}$ Snack food package labels are based on serving or portion size. However, most snack foods are sold in packages containing multiple servings. Furthermore, the "average" container size of a typical convenience store soft-drink beverage has in- 
Table 1. Nutrition Information Labels from Snack Food Packages Used in the Study

\begin{tabular}{|c|c|c|c|c|c|c|}
\hline Product & $\begin{array}{l}\text { Serving } \\
\text { Size }\end{array}$ & $\begin{array}{l}\text { Package } \\
\text { Size }\end{array}$ & $\begin{array}{l}\text { Cal/ } \\
\text { Serving }\end{array}$ & $\begin{array}{r}\text { Calculated } \\
\text { Cal/Package }\end{array}$ & $\begin{array}{l}\text { Fat Cal\% } \\
\text { FDA/Serving }\end{array}$ & $\begin{array}{c}\text { Fat Cal\% } \\
\text { FDA/Package }\end{array}$ \\
\hline $\begin{array}{l}\text { Doritos Nacho Cheesier } \\
\text { Tortilla Chips }\end{array}$ & 1 ounce & 3.25 ounces & 140 & 455 & $11 \%$ & $36 \%$ \\
\hline Milky Way Big Bar & $\begin{array}{l}1 / 3 \mathrm{bar} \\
(34 \mathrm{~g})\end{array}$ & $\begin{array}{l}363 \text { ounces } \\
(102 \mathrm{~g})\end{array}$ & 160 & 480 & $9 \%$ & $27 \%$ \\
\hline $\begin{array}{l}\text { GrandMa's Vanilla Sandwich } \\
\text { Cremes (3 ounce) }\end{array}$ & $\begin{array}{l}5 \text { cookies } \\
(43 \mathrm{~g})\end{array}$ & $\begin{array}{l}10 \text { cookies } \\
(86 \mathrm{~g})\end{array}$ & 210 & 420 & $15 \%$ & $30 \%$ \\
\hline Pepsi & 8 ounce & 20 ounces & 100 & 250 & N/A & N/A \\
\hline
\end{tabular}

creased from 6.5 ounces in the 1950s to 20 ounces (or more) today. ${ }^{4} \mathrm{We}$ postulate that this trend has obscured the distinction between unit size and portion or serving size. (For example, a typical bag of potato chips from a convenience store now contains 3 or more servings). This observation led to our research question: do patients in a general medical practice make the distinction between serving size and package size when consuming snack foods? Stated another way: our hypothesis is that patients make the error of equating "calories per serving" with calories per package. Because this equation is not true for most of snack packages and beverages presently sold, patients may not recognize when they consume multiple servings of a snack food at one sitting. We examined this hypothesis by presenting adult patients in our family practice clinic with a series of questions to determine whether they could identify and correctly use information on actual snack food package labels.

\section{Methods}

A convenience sample of adult patients between the ages of 18 and 65 presenting for medical care at the University of Tennessee/St. Francis Family Practice Center in June 2001 were invited to participate in the study. The University of Tennessee Health Sciences Center Institutional Review Board granted approval of this study. Informed consent was obtained from all patients who volunteered to participate in the study. A total of 100 patients were enrolled, and 90 patients completed the entire survey with the investigator. Participants were first given a questionnaire collecting demographic data and patient health information (self-reported). Participants were asked to state their estimated consumption per week of snack foods and beverages, television viewing habits, and weekly amount of exercise.
Participants were interviewed in person by one of the authors (WWC). Each participant was shown photocopies of nutrition information from an assortment of snack food packages. We selected one beverage, bottled for convenience sale, and a selection of 3 prepackaged, commonly available snack food items. Each product package contained multiple servings (ranging from 2 to 3.5 servings per package). Information taken directly from package labels of the products we presented is reproduced in Table 1. Participants were asked a series of questions to determine their ability to correctly interpret nutrition information from the product labels on display. The interview was conducted with minimal prompting and assistance from the interviewer. Initial incorrect interpretations of the nutrition label were not corrected but simply noted. The participants who initially failed to recognize the packages contained multiple servings were prompted to re-evaluate, and their response was again noted. The structure of the complete interview process is outlined in Table 2.

The primary outcome measure was the participants' final assessment of the total calories in each snack food package and beverage container, based on their interpretation of the nutrition information

\section{Table 2. Study Interview Questions}

1. Do you know, or can you guess, how many calories are in this package?

2. Do you know where you can find this information on the package? (Show if answer is no)

3. Can you tell how many calories are in the entire package now? (Paper, calculation assistance offered only if requested)

4. Can you tell if there is any fat in the product? If so, how much?

5. Do you know how many calories you should consume in a day? How many grams of fat in a day?

6. Do you know, or can you figure out, what portion of your daily calorie or fat allotment is in this package? 
label. Patients who read the "calories per serving line" as equal to the total package calorie content were scored as "no" (for incorrect interpretation). Patients who ultimately noted that there are multiple servings per package were scored as "yes" for a correct interpretation, even if they had given an initially incorrect interpretation or had difficulty calculating the exact number of calories in the package.

The interview process also asked the participant to interpret the fat content on the nutrition label. However, it quickly became apparent that confusion about fat calories per package paralleled confusion about calorie content. Therefore, only data on participants' understanding on calories per package was collected and reported as a proxy to understand how well these patients understood the nutrition information label.

Secondary outcome measures were based on correlations between correct or incorrect understanding (of total calories per package) with data collected from the patient survey. Data were analyzed using SAS, version 8 , with $\chi^{2}$ analysis and Fischer exact test for correlation of label understanding with educational background, exercise, television viewing habits, obesity, and comorbid medical conditions.

\section{Results}

Patients reported consuming, on average, 2 fastfood type snacks per day (beverage or packaged snack foods). The majority of our sample patients are sedentary, exercising fewer than 3 times per week. The mean self-reported TV viewing of our sample was 25.4 hours per week. Our patient sample included a significant number that were overweight. The BMI was calculated for 83 patients, and the mean BMI was 28.5. Many of our patients had one or more chronic medical disorders in which lifestyle, diet, and nutrition are known to play a major role, such as diabetes, hypertension, and cardiovascular heart disease (CHD). Demographic and socioeconomic data, self-reported habits, and self-reported health information is summarized in Table 3.

Eighty-one of 90 patients interviewed (91\%) knew where to find nutrition information on packaged foods and could correctly identify the line on the nutrition label indicating calories per serving. However, 77 (86\%) initially incorrectly identified
Table 3. Characteristics of Study Sample

\begin{tabular}{|c|c|c|}
\hline \multicolumn{3}{|l|}{ Demographic } \\
\hline \multicolumn{3}{|l|}{ Sex } \\
\hline Male & $\mathrm{n}=17$ & $19 \%$ \\
\hline Female & $\mathrm{n}=73$ & $81 \%$ \\
\hline \multicolumn{3}{|l|}{ Race } \\
\hline African American & $\mathrm{n}=38$ & $42 \%$ \\
\hline White & $\mathrm{n}=43$ & $48 \%$ \\
\hline Other & $\mathrm{n}=9$ & $10 \%$ \\
\hline Age & 18 to 60 (mean 36.2$)$ & \\
\hline \multicolumn{3}{|l|}{$\begin{array}{l}\text { Annual Income (Missing } \\
\qquad \mathrm{n}=19)\end{array}$} \\
\hline$<\$ 10,000$ & $\mathrm{n}=18$ & $25 \%$ \\
\hline$\$ 10,000$ to 30,000 & $\mathrm{n}=44$ & $62 \%$ \\
\hline$>\$ 30,000$ & $\mathrm{n}=9$ & $13 \%$ \\
\hline \multicolumn{3}{|l|}{ Education } \\
\hline Less than high school & $\mathrm{n}=23$ & $26 \%$ \\
\hline High school/equivalent & $\mathrm{n}=51$ & $57 \%$ \\
\hline Beyond high school & $\mathrm{n}=15$ & $17 \%$ \\
\hline \multicolumn{3}{|l|}{$\begin{array}{l}\text { Habits, self-report (group } \\
\text { mean) }\end{array}$} \\
\hline Daily snack food/beverage & 2 units per day & \\
\hline Exercise frequency & 3 times per week & \\
\hline TV viewing per week & 25.4 hours per week & \\
\hline BMI (calculated) & 28.4 & \\
\hline \multicolumn{3}{|l|}{$\begin{array}{l}\text { Co-morbid medical conditions, } \\
\text { self-report (missing } \\
\mathrm{n}=11 \text { ) }\end{array}$} \\
\hline Diabetes & $\mathrm{n}=17$ & $21 \%$ \\
\hline Hypertension & $\mathrm{n}=29$ & $37 \%$ \\
\hline Coronary heart disease & $\mathrm{n}=6$ & $8 \%$ \\
\hline $\begin{array}{l}\text { Stroke/cerebrovascular } \\
\text { disease }\end{array}$ & $\mathrm{n}=3$ & $4 \%$ \\
\hline $\begin{array}{l}\text { Chronic obstructive lung } \\
\text { disease }\end{array}$ & $\mathrm{n}=0$ & $0 \%$ \\
\hline Hyperlipidemia & $\mathrm{n}=24$ & $30 \%$ \\
\hline
\end{tabular}

the total package calorie content equal to "calories per serving." With prompting, some patients corrected this initial error, but a large majority (57 of 90 , or $63 \%$ ) still in the end confused calories per serving with total calories per package. Patients who had not completed high school were less likely to correctly identify total calories in a package based on the label information $(P=.011)$. Inability to correctly identify total calories in the package was also associated with the presence of CHD in our patient sample $(P<.05)$ (Table 4$)$. No significant association was found between incorrect interpretation of package information and race/ ethnicity, gender, marital status, television viewing habits, exercise, obesity, and self-reported presence of chronic diseases other than CHD.

\section{Discussion}

A recent study has suggested a strong link between snack food consumption and adolescent obesity. ${ }^{10}$ Like other studies, however, this was based on a 
Table 4. Significant Associations with Incorrect Interpretation of Package Label

\begin{tabular}{lcc}
\hline & $\begin{array}{c}\text { Unable to } \\
\text { identify } \\
\text { multiple } \\
\text { servings per } \\
\text { package }\end{array}$ & $\begin{array}{c}\text { Able to identify } \\
\text { multiple } \\
\text { servings per } \\
\text { package }\end{array}$ \\
\hline Cardiovascular disease & & \\
$\quad$ Not reported & 51 & 33 \\
$\quad$ Reported & 6 & 0 \\
$(P<.05)$ & & \\
Level of education & & 10 \\
$\quad$ Bachelor's degree & 4 & 6 \\
$\quad$ High school or equivalent & 35 & \\
$\quad$ Didn't complete high school & 18 & \\
$(P=.011)$ & & \\
\hline
\end{tabular}

There was a significant difference in the ability to identify multiple servings per package in those with at least a high school diploma versus those that did not complete high school.

recall of food consumption. No studies that we are aware of have examined how a typical general practice patient population understands and uses (or does not) snack food nutrition information. An overwhelming majority of patients in this sample does not understand the distinction between "serving size" and "package/container size" of prepackaged snack foods and beverages. Thus, they believe they are consuming a single serving of snack food per package when in fact they are not. Patients with less education seem to be especially at risk of making this mistake.

Based on self-reported snack food intake of 2 units daily, our patients consume an average of 4 to 6 servings of snack food per day without realizing that they are doing so. The average patient in our study thus consumes (conservatively) 600 to 1000 calories daily from snack food sources. The consequences of this excess caloric intake over time can be highly significant. Because few physicians routinely ask patients about snack food intake, the impact of this on weight and weight-related disorders is very likely to be hidden or overlooked.

Many physicians can relate tales of obese patients who consume large amounts of sugar and caffeine-laden beverages or multiple packages of prepackaged snacks, yet these same patients genuinely seem to have no concept of the effect that this has on their health. Our study may provide an explanation for this phenomenon. It is surprising how little systematic study has been done on snack food intake and its impact on health in actual medical practice. This study suggests the need for bet- ter education of patients on this matter, and the need for physicians to specifically ask about snack food intake among patients in their practice. Finally, this study calls into question the utility of snack food package labeling itself.

Our study relies in part on patients' self-report of food intake and related habits, which may be misleading. However, recent studies have shown that overweight persons tend to under-report caloric energy intake. ${ }^{5}$ In addition, the personal interviews allowed us to correct for any recall bias by directly testing participant's knowledge about serving versus package size.

The assumption has been that consumers can correctly use nutrition label information to distinguish between serving size and unit/package size, and use this information to make informed choices about their eating habits. Our survey suggests that this assumption is incorrect. We find that the overwhelming majority of our patients do not understand snack food nutrition labels well enough to make informed dietary choices. This is especially striking in our patients with limited education, who tend to be most at risk for nutrition-related disorders. Further research into this area is needed. The role of advertising and the effects of the widespread availability of snack food are other factors to consider. The results of such clinical research could lead to better understanding and management of obesity in this country.

\section{References}

1. Centers for Disease Control and Prevention [homepage on the Internet]. Atlanta: Centers for Disease Control and Prevention; 2003 [updated 2003 Nov 5; cited 2004 Jun 25]. National Center for Chronic Disease Prevention and Health Promotion. Behavioral Risk Factor Surveillance System. Available from: http://apps.nccd.cdc.gov/brfss/trends/ trenddata.asp

2. Mokdad AH, Bowman BA, Ford ES, Vinicor F, Marks JS, Koplan JP. The continuing epidemics of obesity and diabetes in the United States. JAMA 2001;286:1195-200.

3. US Department of Health and Human Services. The Surgeon General's call to action to prevent and decrease overweight and obesity. Rockville (MD): U.S. Department of Health and Human Services, Public Health Service, Office of the Surgeon General; 2001. Available from: http://www.surgeongeneral.gov/ topics/obesity/calltoaction/CalltoAction.pdf

4. Nielsen SJ, Barry MP. Patterns and trends in food portion sizes, 1977-1998. JAMA 2003;289:450-3. 
5. Young LR, Nestle N. The contribution of expanding food portion sizes to the US obesity epidemic. Am J Public Health 2002;92:246-9.

6. Levy L, Patterson RE, Kristal AR, Li SS. How well do consumers understand percentage daily value on food labels? Am J Health Promot 2000;14:157-60.

7. Reid DJ, Hendricks SM. Consumer understanding and use of fat and cholesterol information on food labels. Can J Public Health 1994;85:334-7.

8. Marietta AB, Welshimer KJ, Anderson SL. Knowledge, attitudes, and behaviors of college students regarding the 1990 Nutrition Labeling Education Act food labels. J Am Diet Assoc 1999;99:445-9.

9. Brecher SJ, Bender MM, Wilkening VL, McCabe NM, Anderson EM. Status of nutrition labeling, health claims, and nutrient content claims for processed foods: 1997 Food Label and Package Survey. J Am Diet Assoc 2000;100:1057-62.

10. Ludiwg DS, Peterson KE, Gortmaker SL. Relation between consumption of sugar sweetened beverages and childhood obesity: a prospective, observational analysis. Lancet 2001;357:505-8. 